\title{
Desensitization in kidney transplantation: Review
}

\author{
Jamilya Saparbay $^{1}$, Mels Assykbayev ${ }^{1}$, Saitkarim Abdugafarov ${ }^{1}$, Gulnur Zhakhina ${ }^{1}$, Janat Spatayev ${ }^{1}$, \\ Asan Zhexembayev ${ }^{1}$, Zhuldyz Zhanzakova ${ }^{2}$, Aida Turganbekova ${ }^{2}$, Saniya Abdrakhmanova ${ }^{2}$, Gulnara Kulkayeva ${ }^{1}$
}

${ }^{I}$ Department of Organ Transplantation, National Research Oncology Center, Nur-Sultan, Kazakhstan

${ }^{2}$ Department of Immunological Support of Organ Transplantation, Research and Production Center for Transfusiology, Nur-Sultan, Kazakhstan

Received: 2021-11-12.

Accepted: 2021-12-09

This work is licensed under a Creative Commons Attribution 4.0 International License

\section{J Clin Med Kaz 2021; 18(6):32-34}

Corresponding author: Jamilya Saparbay.

E-mail: dzhamilyasaparbay@gmail.com; ORCID: 0000-0002-8478-5452

\section{Abstract}

Sensitization to human leukocyte antigens (HLA) antigens is the main obstacle to getting the kidney either from a living or deceased donor. HLA sensitization occurs as the result of repeated pregnancy, blood transfusion, or previous transplantation. Overcoming the HLA incompatibility is one of the approaches to decrease the organ shortage. There are 3.5\% highly sensitized patients among 3012 patients on the waiting list for kidney transplantation in Kazakhstan.

In this review, we have discussed most common approaches of desensitization for HS kidney recipients. Huge progress has been made in the field of desensitization in transplant medicine worldwide. We suppose, that implementation the desensitization protocols in clinical guidelines will improve patient survival and outcome after kidney transplantation.

Key words: kidney transplantation, HLA sensitization, immunology

\section{Introduction}

In the last decade, organ transplantation is developing fast in Kazakhstan. Internationally approved guidelines are used in all transplant centers in Kazakhstan. According to the Global Burden of Disease Study, the number of chronic kidney disease (CKD) patients is one million individuals, which is equal to $5.5 \%$ of the general population [1]. Nearly 100 kidney transplantations from living donors and 30 kidney transplantations from deceased donors are performed annually in Kazakhstan. Currently, 3012 patients are waiting for kidney transplantation in Kazakhstan [2]. In Kazakhstan there is a burden of organ shortage, mostly due to the low rate of cadaveric transplantation, this feature is very common for all Asian countries [3]. Moreover, there is one more obstacle for recipients to receive either cadaveric or living graft- sensitization to the human-leucocyte antigens. Totally 416 cases of kidney transplantation were performed in our center. 56 kidneys from deceased donors and 360 from living donors.

The mean waiting time for recipients was 28 months in patients, who underwent transplantation from deceased donors. According to our data, where 416 consecutive kidney transplantations were analyzed, 5-year graft survival in the group of recipients from living donors was $86.58 \%$ and $52 \%$ from cadaveric donors. Thus, in our cohort, living donor kidney transplantation is a preferred treatment choice for patients with end-stage renal disease. However, for many patients with end-stage renal disease (ESRD) sensitization to human leukocyte antigens (HLA) antigens is the main obstacle to getting the kidney either from a living or deceased donor. HLA sensitization occurs as the result of repeated pregnancy, blood transfusion, or previous transplantation [4]. Overcoming the HLA incompatibility is one of the approaches to decrease the organ shortage. There are $3.5 \%$ highly sensitized patients among 3012 patients on the waiting list for kidney transplantation in Kazakhstan. Currently, there are no common guidelines for desensitization used in Kazakhstan. In this review, we discuss the current state of desensitization therapy for patients with HLA antibodies.

\section{Desensitization strategies}

There are no widely accepted guidelines for desensitization. The complex of approaches is used to eliminate circulating anti-HLA antibodies or lowering calculated panel reactive antibody (cPRA) in the plasma of potential kidney recipients (Figure 1). Plasmapheresis or immunoadsorption is used for the elimination of circulating anti-HLA antibodies. Monoclonal antibodies and intravenous immunoglobulin for prolonged inhibition of HLA antibody production. 
Figure 1 - Desensitization mechanism

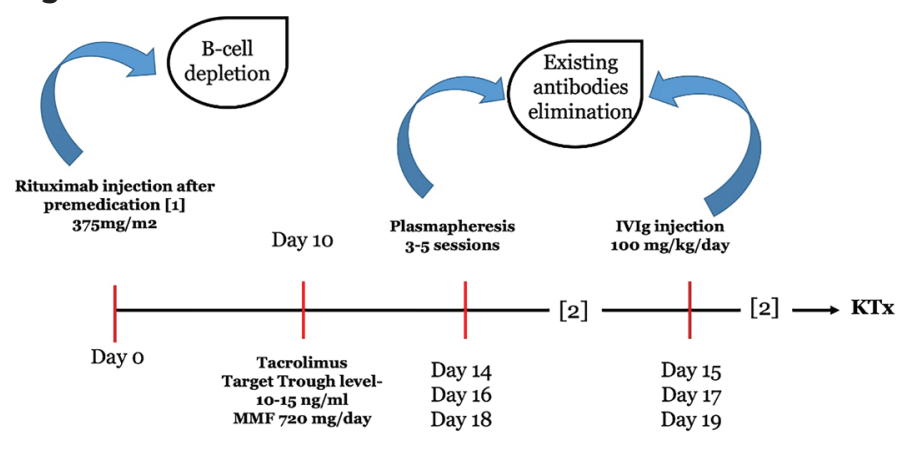

[1]- Allergopress $1 \mathrm{ml}+\mathrm{0}, 9 \% \mathrm{NaCl} 250 \mathrm{ml}$
Prednisolone $28 \mathrm{mg}+19 \mathrm{ml} 0,9 \% \mathrm{NaCl}$

[2] -Check the cross match test + anti HLA

Abs level

\section{Rituximab for desensitization}

In highly sensitized patients, memory B cells and plasma cells can be targets for desensitization therapies. Memory B cells respond to donor-specific HLA, while plasma cells produce antibodies against HLAs [5]. One of the B cell markers, CD20 phosphoprotein, is found on both normal and malignant cells. Although the exact biological function of CD20 and its ligand is unclear, since it is expressed relatively constant on both normal and cancerous B cells, CD20 is an attractive therapeutic target [6,7]. In 1997, the Food and Drug Administration approved rituximab as an anti-CD20 antibody, which brought progress in the management of cancerous diseases [8]. Rituximab interrupts the $\mathrm{B}$ cell receptor signaling process, which brings the depletion of short-lived plasma cells in the blood in a short term, and depletion of CD27+ cells in the long-term effect [5].

\section{Bortezomib for desensitization}

Although rituximab is proved as an effective monoclonal antibody, there are cases when long-lived plasma cells (LLPC) also produce donor-specific HLA antibodies (DSA) [9]. They can produce antibodies whole life; therefore, they play an important role in antibody-mediated rejection (ABMR). Since LLPCs are independent of B-cell precursors, proteasome inhibitors can be used to address the issue of ABMR [9]. Bortezomib (marked as Velcade) was approved by the FDA in 2003 for the treatment of multiple myeloma [10]. It has apoptotic abilities, which inhibit the function of proteasomes, which is crucial against allogeneic HLA [5].

\section{Plasmapheresis and plasma exchange}

Plasma exchange and intravenous immunoglobulin treatment (IVIG) are widely used in desensitization protocols along with rituximab for patients with an incompatible crossmatch to reduce the effect of ABMR [11]. Sometimes additional immunosuppression with bortezomib may be required depending on the level of DSA. The number of plasmaphereses is dependent on the antibody levels and the degree of mismatch [11]. Cascade plasmapheresis is a semi-selective and efficient treatment due to its ability to proceed with higher plasma volume [12]. Moreover, the risk for a patient is negligible because there are minimal requirements for a substitution fluid [11]. There is strong evidence of the positive effect of plasmapheresis on the survival of highly sensitized patients $[13,14]$.

\section{IVIG}

Intravenous immunoglobulin (IVIG) is a blood product, which is widely used as a therapy option for patients, who experience antibody deficiency. The mechanism of action of therapeutic immunoglobulin depends on its dose and the type of disease [15]. Gamma globulin fraction of blood plasma produces IVIG, which inhibits T- and B-cell proliferation, cytokine production, and induces B-cell apoptosis $[16,17]$. These functions make IVIG an ideal agent for desensitization therapy. Desensitization protocols can have two general approaches: high dose IVIg or low dose IVIG combined with plasmapheresis and rituximab [18]. Although researchers declare improved survival rates and decreased graft loss, the biological pathways of desensitization agents are complex; therefore, the protocols are unstandardized, and the efficacy remains variable [19-22].

\section{Discussion}

Historically, attempts to overcome the HLA sensitization were initiated in early 1900-s [23]. The necessity of desensitization protocols implementation was dictated by increasing rate of highly sensitized patients. Patients, with a panel reactive HLA antibody level above $80 \%$ are defined as highly sensitized (HS) kidney recipient candidates. According to the United Network for Organ Sharing (UNOS), approximately 30\% of the patients on the wait list are considered highly sensitized. Currently, only $6.5 \%$ of patients with a panel reactive HLA antibody (PRA) levels above $80 \%$ [i.e. highly sensitized (HS)] receive a transplant each year [24]. The patient cohort remain on dialysis, mortality rate is higher in comparison with HS patients, who underwent transplantation after desensitization. Vo et al reported that mean waiting time on dialysis in their cohort of HS patients was $114 \pm 56$ months before desensitization and $4.4 \pm 4.9$ months after desensitization [25]. According to the URSDS Renal Data System Report, the average wait times for cadaveric renal transplantation are long for sensitized patients with ESRD (4 to 5 years), but nearly exclusionary for high sensitized patients [26].

Another multicenter study by Orandi et al., stated that recipients of kidney transplants from incompatible live donors after desensitization had a significant survival benefit as compared with the waiting-list-or-transplant control group and the waiting-list-only control group $(\mathrm{P}<0.001$ for both comparisons [27]. Regarding cost-effectiveness, multivariate analysis by Vo et al. showed 3-year savings based on a 3.4\% Cedars-Sinai mortality rate for desensitized patients remaining on dialysis, is $\$ 15,428$ per desensitized and transplanted patient.

In Kazakhstan, there are no generally accepted desensitization protocols. However, in Kazakhstan HS patients still have low possibility to get kidney either from deceased or living donor. Currently, desensitization drugs cannot be provided within the guaranteed volume of medical care that leads to high mortality on dialysis among HS ESRD patients.

In this review, we have discussed most common approaches of desensitization for HS kidney recipients. Huge progress has been made in the field of desensitization in transplant medicine worldwide. We suppose, that implementation the desensitization protocols in clinical guidelines will improve patient survival and outcome after kidney transplantation.

Disclosures: There is no conflict of interest for all authors.

Funding: None.

Acknowledgments: None. 


\section{References}

1. Organization WH. Noncommunicable diseases (NCD) country profiles 2018: Kazakhstan. Geneva. Available at http//www.whoint/nmh/ countries/2018/irq_en.pdf: World Health Organization; 2018

2. RSE on PCV "Republican center for coordination of transplantation and high-tech medical services" of the Ministry of health of the Republic of Kazakhstan. URL: https://transplant.kz/ru/statistika

3. Jager KI, Kovesdy C, Langham R, Rosenberg M, Jha V, Zoccali C. A single number for advocacy and communication- worldwide more than 850 million individuals have kidney diseases. Nephrol Dial Transplant. 2019; 34(11):1 803-5. DOI: 10.1093/ndt/gfz174

4. Cai J, Terasaki PI. The current trend of induction and maintenance treatment in patient of different PRA levels: a report on OPTN/UNOS Kidney Transplant Registry data. Clin Transpl. 2010;45. PMID: 21696031

5. Ide, K., Tanaka, Y., Sasaki, Y., Tahara, H., Ohira, M., Ishiyama, K., \& Ohdan, H. (2015). A phased desensitization protocol with rituximab and bortezomib for highly sensitized kidney transplant candidates. Transplantation direct, 1(5). doi: 10.1097/TXD.0000000000000526

6. Pavlasova, G., \& Mraz, M. The regulation and function of CD20: an "enigma” of B-cell biology and targeted therapy. Haematologica. 2020; 105(6):1494. doi: 10.3324/haematol.2019.243543

7. Macklin, P. S., Morris, P. J., \& Knight, S. R. A systematic review of the use of rituximab for desensitization in renal transplantation. Transplantation. 2014; 98(8):794-805. DOI: 10.1097/TP.0000000000000362

8. Casan, J. M. L., Wong, J., Northcott, M. J., \& Opat, S. Anti-CD20 monoclonal antibodies: reviewing a revolution. Human vaccines \& immunotherapeutics. 2018; 14(12):2820-2841. DOI: 10.1080/21645515.2018.1508624

9. Su, H., Zhang, C. Y., Lin, J. H., Hammes, H. P., \& Zhang, C. The role of long-lived plasma cells in antibody-mediated rejection of kidney transplantation: an update. Kidney Diseases. 2019; 5(4):211-219. DOI: 10.1159/000501460

10. Kane, R. C., Bross, P. F., Farrell, A. T., \& Pazdur, R. Velcade ${ }^{\circledR}$ : US FDA approval for the treatment of multiple myeloma progressing on prior therapy. The oncologist. 2003; 8(6):508-513. DOI: 10.1634/theoncologist.8-6-508

11. Clark, W. F., Huang, S. H. S., Walsh, M. W., Farah, M., Hildebrand, A. M., \& Sontrop, J. M. (2016). Plasmapheresis for the treatment of kidney diseases. Kidney international. 2016; 90(5):974-984. doi.org/10.1016/j.kint.2016.06.009

12. Bajpai, M., Kakkar, B., Gupta, S., Rastogi, A., \& Pamecha, V. Cascade plasmapheresis as a desensitization strategy for patients undergoing ABO incompatible living donor liver transplantation (ABOi LDLT): A single center experience. Transfusion and Apheresis Science. 2019; 58(4):442-446. DOI: 10.1016/j.transci.2019.04.028

13. Montgomery RA, Lonze BE, King KE, et al. Desensitization in HLA- incompatible kidney recipients and survival. $N$ Engl J Med. 2011; 365:318-326. DOI: 10.1056/NEJMoa1012376

14. Orandi BJ, Luo X, Massie AB, et al. Survival benefit with kidney transplants from HLA-incompatible live donors. $N$ Engl J Med. 2016; 374:940-950. DOI: 10.1056/NEJMoa1508380

15. Jolles, S., Sewell, W. A. C., \& Misbah, S. A. Clinical uses of intravenous immunoglobulin. Clinical and experimental immunology. 2005; 142(1):1. DOI: 10.1111/j.1365-2249.2005.02834.x

16. Kazatchkine, M. D., \& Kaveri, S. V. Immunomodulation of autoimmune and inflammatory diseases with intravenous immune globulin. New England Journal of Medicine. 2001; 345(10):747-755. DOI: 10.1056/NEJMra993360

17. Watanabe, J., \& Scornik, J. C. IVIG and HLA antibodies. Evidence for inhibition of complement activation but not for anti-idiotypic activity. American journal of transplantation. 2005; 5(11):2786-2790. DOI: 10.1111/j.1600-6143.2005.01056.x

18. Kuppachi, S., \& Axelrod, D. A. Desensitization strategies: is it worth it? Transplant International. 2020; 33(3):251-259. DOI: 10.1111/ tri. 13532

19. Jordan, S. C., Legendre, C., Desai, N. M., Lorant, T., Bengtsson, M., Lonze, B. E., ... \& Montgomery, R. A. Imlifidase Desensitization in Crossmatch-positive, Highly Sensitized Kidney Transplant Recipients: Results of an International Phase 2 Trial (Highdes). Transplantation. 2021; 105(8):1808. DOI: 10.1097/TP.0000000000003496

20. Orandi BJ, Garonzik-Wang JM, Massie AB, et al. Quantifying the risk of incompatible kidney transplantation: a multicenter study. Am J Transplant. 2014; 14:1573-1580. DOI: 10.1111/ajt.12786

21. Patel S, Benken J, West Thielke P, et al. Three year outcomes following positive cross match renal transplantation despite failure to convert to negative flow cross match after desensitization. J Clin Nephrol. 2018; 2:29-38. DOI: 10.29328/journal.jcn.1001016

22. Marfo K, Lu A, Ling M, et al. Desensitization protocols and their outcome. Clin J Am Soc Nephrol. 2011; 6:922-936. DOI: 10.2215/ CJN.08140910

23. Marfo K, Lu A, Ling M, et al. Desensitization protocol and their outcomes. Clin J Am Soc Nephrol. 2011; 6:922,2011. DOI: 10.2215/ CJN.08140910

24. Organ Procurement and Transplantation Network (OPTN).Scientific Registry of Transplant Recipients. 2012 Annual Data Report,2012);Scientific Registry of Transplant Recipients http://srtr.transplant.hrsa.gov/Resouces.aspx (9 January 2014, date last accessed)

25. Vo AA Choi J Cisneros Ket et al. Rituximab and intravenous immune globulin for desensitization during renal transplantation. $N E n g l$ J Med. 2008; 359:242-51. DOI: 10.1056/NEJMoa0707894

26. USRDS Renal Data System Report,2001

27. Orandi B.J.; Luo X., Massie A.B.; Garonzik-Wang J.M.; Lonze B.E. Survival Benefit with Kidney Transplants from HLA-Incompatible Live Donors. 374:940-50). DOI: 10.1056/NEJMoa1508380 